ano 6 - número 7 - 2008

\title{
EM TEMPOS DE DESPOSSESSÃO, PRECARIEDADES NA EDUCAÇÃO COMO POLÍTICA DE ESTADO E NO PETI COMO POLÍTICA DE GOVERNOS'.
}

FONSECA, Laura Souza - I.sfonseca@uol.com.br

Analiso as relações entre a exploração do trabalho infanto-juvenil vincado na precariedade das políticas de Estado, particularizando Educação e Assistência Social, e a proliferação de políticas de governo na atualidade do processo capitalista de acumulação por despossessão ${ }^{2}$. Brevemente, situo os conceitos de infância e adolescência em diferentes estruturas apreendendo a maneira pela qual os lugares geracionais foram sendo expressos na batalha das idéias em diferentes tempos da acumulação capitalista; lastro para a luta de concepções e práticas políticas, sobre o lugar/tempo da escola e do trabalho para crianças e adolescentes da classe trabalhadora. Disputas feitas no marco de políticas de Estado que, cada vez mais, vêm sendo atravessadas por infinidade de programas e projetos de governo. Aqui problematizo as conexões entre trabalho infanto-juvenil, escola pública, socioeducativo ${ }^{3} \mathrm{e}$ PETI (Programa de Erradicação do Trabalho Infantil).

Situando as idades da vida como totalidades sócio-históricas, portanto definidas na medida em que cada tempo, cada sociedade produz concepções próprias e atribui práticas específicas a cada uma delas; tendo como mediação (Ciavatta, 2001) a categoria classe social. A disputa de ideais marcará, também, a interface entre trabalho e educação e alguns dos conceitos que as vinculam: politecnia, trabalho educativo, iniciação à aprendizagem profissional, estágios, etc.

Com este movimento dou densidade à idéia de que o trabalho como organizador da vida no tempo infanto-juvenil para quem vive da venda de sua força de trabalho assujeita para uma precária inserção no mundo do trabalho. Sutil ruptura na potencialidade do ser social infanto-juvenil, fortalecida pelo simulacro do trabalho [como princípio] educativo e formação politécnica na Educação, ou (re) visitada na Assistência Social. Desqualificam o trabalho e,

\footnotetext{
${ }_{2}^{1}$ Ensaio que retoma trabalho apresentado no XIV ENDIPE (2008).

2 A partir de Harvey, como expropriação, roubo: acumulação mediante golpes no fundo público por falências fraudulentas, privatizações, reformas do Estado... todas formas de acumular capital (des)apossando a classe trabalhadora materialmente e no campo dos direitos humanos e sociais (Harvey, 2004 e 2005).

${ }^{3}$ Apoio socioeducativo - política protetiva às vidas infanto-juvenis no turno inverso à escola, parte do acordo para receber bolsa PETI em que recebe a nomeção de jornada ampliada.
} 
issn: $1808-799 \mathrm{X}$

ano 6 - número 7 - 2008

nesse sentido, a vida e as perspectivas formativas para inserção de qualidade em toda e qualquer atividade produtiva: potencializam a formação de sobrantes ${ }^{4}$ no e do sistema produtivo, justificando a proliferação de projetos sociais de controle social, compensatórios, focais e assistencialistas.

\section{DIFERENCIAÇÃO DO TEMPO INFANTO-JUVENIL E ACUMULAÇÃO CAPITALISTA}

No final do século XVI e início do XVII, homens, mulheres e crianças expulsas da terra engrossaram as fileiras nas periferias das cidades e, para sobreviverem, vendiam sua força de trabalho nas manufaturas e primeiras indústrias. O fenômeno descrito por Marx como de acumulação primitiva, define o processo histórico de apartação entre produtor e meios de produção. Nas sociedades pré-industriais a criança era apenas uma possibilidade remota, um vir a ser adulto no cotidiano doméstico, não aparecia publicamente longe dos cuidados familiares e, neste sentido, não representava uma subjetividade social. Apenas quando se tornou força de trabalho com interesse para o capital começou a ganhar autonomia em relação à família; primeiro, obrigada a trabalhar mas com o desenvolvimento da grande indústria e a luta da classe trabalhadora pela regulamentação da jornada de trabalho vai sendo liberada da fábrica. Contexto de formulação de políticas para a infância pelos movimentos socialistas, quando na fábrica as crianças eram escravizadas, exploradas, abandonadas e mal cuidadas. $\mathrm{E}$, ao tempo em que foram dispensadas do chão da fábrica pela maquinaria e como conquista da luta de classes; não encontram lugar na escola, sobrando-lhes andarilhar pelas ruas.

A revolução industrial do século XVIII utilizando energia hidráulica e máquina a vapor elevou a produtividade e desenvolveu a indústria têxtil e a construção de ferrovias. Junto às mudanças técnicas, seguiram mudanças nas relações sociais, um tempo de uso abusivo do trabalho de mulheres e crianças, cujo salário podia equivaler a metade ou a terça parte da remuneração de um trabalhador adulto (Engels, 2003), fazendo parte de uma incipiente classe operária, assalariados dividindo um mesmo local de trabalho, com disciplina e vigilância. A divisão social do trabalho que substancia o processo de acumulação do capitalismo compõe o eixo sobre o qual Marx e Engels expõem as questões da educação e do ensino com vistas à emancipação social e, com essa, a emancipação humana. Os dois pensadores revolucionários tratam de reivindicações em torno da obrigatoriedade e gratuidade do ensino e da delimitação

\footnotetext{
${ }^{4}$ Exército de reserva de trabalho, exército industrial de reserva, ou superpopulação relativa. Para Marx (1991), a existência de uma reserva de força de trabalho desempregada e parcialmente empregada ou potencialmente desempregada é uma característica inerente à sociedade capitalista, criada e reproduzida diretamente pela própria acumulação de capital.
} 
issn: $1808-799 \mathrm{X}$

ano 6 - número 7 - 2008

do tempo de trabalho para crianças e adolescentes e, no mesmo escopo, trazem como base da proposta educativa a união do trabalho manual ao trabalho intelectual. Avançam na perspectiva de um novo patamar para a ciência e para a família superando as concepções ideológicas estabelecidas.

Em O Capital, quando Marx (1991) discutiu as conseqüências imediatas da industrialização para os operários, chamou atenção que a maquinaria, ao minimizar a força muscular, admite trabalhadores sem desenvolvimento físico completo, com flexibilidade de seus membros. Assim, a tecnologia criada para eliminar trabalho humano convertia-se em multiplicação de assalariados, colocando todos os indivíduos da família operária, sem distinção de sexo nem idade, sob a dependência imediata do capital. Ao invés de gerar tempo livre para o trabalhador usufruir a vida, suga a família para o trabalho fabril. Engels (2003) refere à transformação das famílias da classe trabalhadora em função da industrialização - o ingresso no trabalho fabril altera as funções maternas de cuidado dos filhos e da casa; os cuidados com os filhos pequenos e a amamentação precisaram ser substituídos porque a mãe estava na fábrica. Os valores de uso produzidos pela família são substituídos pelos valores de troca produzidos pela indústria, aumentando os custos de sustento.

Criam-se refúgios para guardar crianças; surgem organizações para cuidar de lactentes. No final do século XVII apareceram as primeiras creches urbanas na França e Inglaterra, sob a ótica assistencialista, visavam afastar as crianças pobres do trabalho servil que a expansão capitalista impunha, servindo também como guardiãs de órfãs e filhos de trabalhadores. A guarda e a educação das crianças tomam a cena da legislação social e das reformas escolares desde o século XVIII até hoje. As crianças e adolescentes da classe trabalhadora iniciam sua perambulação entre a necessidade material do trabalho precoce e a luta pelo direito a uma vida infantil desfrutando da escolar (idade).

\section{ACUMULAÇÃO FORDISTA-TAYLORISTA: DO CHÃO DA FÁBRICA AO CHÃO DA ESCOLA}

Ao expor a mais-valia absoluta, o trabalho excedente e a produção de mais-valia relativa no desenvolvimento da maquinaria e da grande indústria, Marx (1991) descreve as lutas operárias na Inglaterra fazendo a disputa de legislação da jornada nas fábricas. Realidade em que introduz a temática do trabalho infantil, uma vez que os capitalistas jogavam com o trabalho de mulheres e crianças durante os quase cinqüenta anos em que se constitui esta legislação. Na Crítica ao Programa de Gotha, Marx (s/d) traz a "restrição do trabalho da mulher e proibição do trabalho infantil", referindo à incoerência dessa discussão estar separada do 
issn: $1808-799 X$

\section{ano 6 - número 7 - 2008}

tema da jornada de trabalho como um todo. Aponta ainda que a regulamentação da jornada de trabalho da mulher precisa estar associada à duração, descanso e ramos de produção compatíveis com seu organismo e convenientes do ponto de vista moral e sexual. Quanto à proibição geral do trabalho infantil, diz que a generalidade é incompatível com a grande indústria - acreditava que o desenvolvimento da indústria seguiria agregando crianças ao trabalho. Afirma que pôr em prática essa proibição seria reacionário, se factível, já que regulamentada a jornada de trabalho, segundo as idades e aplicando medidas de proteção para as crianças, combinar trabalho produtivo e aprendizagem potencializa transformações na sociedade.

A educação para Marx e Engels vincula trabalho produtivo e ensino, mantendo crítica implacável à exploração e à alienação do trabalho inerentes ao capitalismo. Perspectiva em que se produzem os fundamentos pedagógicos da escola socialista combinando educação profissional e trabalho produtivo e atividade física. Lenin e Krupskaya organizaram a visão educacional marxista como movimento científico-pedagógico vinculado ao projeto socialista. Lenin enfatizou o papel da escola no socialismo afirmando a necessidade de trazer vida e política para a escola ou essa seria "uma mentira e uma hipocrisia". Abordando as tarefas para a juventude comunista, falou de uma escola que assegurasse aquisição dos conhecimentos acumulados pela humanidade - a velha ciência/a velha escola - e trabalho coletivo. Propôs o acervo da velha sociedade como alicerce da educação, partindo desse para, transformando-o, constituir seu próprio acervo. (Lenin, s/d).

Na Escola do Trabalho (Pistrak, 2000), docentes eram militantes ativos e estudantes deveriam compreender seu papel na luta internacional contra o capitalismo, o lugar da classe trabalhadora na disputa e o papel da juventude. Fundada no método dialético, a análise da realidade social, a apropriação dos conhecimentos das ciências naturais, humanas e sociais sistematizados na forma de complexos e na auto-organização dos estudantes - os coletivos infanto-juvenis. Relevando o trabalho socialmente útil determinante das relações sociais de produção, com ênfase em uma formação geral sólida, cuidados com a higiene, organização da escola e da vida, incentivava a compreensão da necessidade do trabalho coletivo - tanto nas tarefas domésticas, quanto nas que envolvessem espaços públicos. Em Poema Pedagógico baseado na experiência de direção na Colônia Gorki, Makarenko destacou auto-organização, disciplina, autoridade e trabalho produtivo como conceitos centrais da pedagogia socialista.

Do campo das concepções e práticas socialistas forjados na revolução bolchevique, 
issn: $1808-799 X$

ano 6 - número 7 - 2008

ficam os grandes eixos fundantes do campo teórico-metodológico marxista para a educação: uma teoria conectada a uma estratégia política revolucionária que, portanto, utiliza-se do método dialético para ler e intervir no mundo; partindo do acúmulo técnico, científico e cultural apropriado pela burguesia, re-apropria-o demarcando as conquistas e possibilidades da/na luta de classes; entranha a escola da política e da vida; afirma a auto-organização dos estudantes como forma de democracia escolar; através da politecnia, toma o conceito marxista de omnilateralidade, de uma formação humana ampla que desenvolva como totalidade o ser social e se articula no encontro entre instrução e trabalho produtivo. Uma educação obrigatória, gratuita e universal em todos os níveis.

ACUMULAÇÃO FLEXÍVEL, UNIVERSALIZAÇÃO ‘DE MENOR’ DA ESCOLA PÚBLICA: SOBRAM O TRABALHO E A RUA.

A reestruturação produtiva na terceira revolução industrial consistiu em mudanças nos meios de produção pelo uso de microeletrônica, rebatendo na informatização, automação e robotização do sistema produtivo; da microbiologia, incidindo sobre a engenharia genética, biotecnologia etc; e novas fontes de energia. Quando agrega valor ao capital constante intensificando trabalho morto, amplia mais-valia relativa; e, do ponto de vista dos trabalhadores, difunde práticas de rodízio e flexibilidade de funções, exige de uma fração da classe trabalhadora alta qualificação profissional e joga a imensa maioria no quantitativo de desempregados - desemprego estrutural que, funcional à acumulação, promove uma crise de superprodução da mercadoria força de trabalho. Um todo que impacta relações sociais e técnicas no processo produtivo, concepções e práticas de poder, valor e ética. Politicamente, acompanhado da desregulamentação do Estado desobrigando-se das políticas públicas terceirizando serviços e privatizando empresas públicas. Paulatinamente, o Estado sob a égide do neoliberalismo e da mundialização financeira deixa ainda mais precário o atendimento ao trabalho e revigora-se como fonte rentável ao capital.

Assim é caso brasileiro. Com base na chamada lei de responsabilidade fiscal, enxugase a folha de servidores/as públicos abandonando a responsabilidade com a face social inscrita no marco contratual desde a Constituição de 1988.

As políticas públicas de Educação referenciadas no mercado estabelecem a profissionalização como eixo no $2^{\circ}$ grau (a lei 5692/71). Na formação profissional as escolas técnicas e agrotécnicas de nível médio estão orientadas pela ideologia do capital humano: investimento no indivíduo, executada de forma produtivista, dualista e fragmentária. Frigotto 
issn: $1808-799 X$

ano 6 - número 7 - 2008

(1989), analisando a educação nas décadas de 1970 e 1980, destaca: enfoques economicistas que reduzem a educação a fator de produção, a capital humano, marcando uma escola absolutamente produtiva para a ideologia do capital e improdutiva para as necessidades da classe trabalhadora.

Uma política orientada por organismos internacionais para a formação de decodificadores e consumidores da produção em ciência e tecnologia. Aqui a ciência e o conhecimento aparecem como um dado e não como um processo. Nos vínculos entre economia e educação, educação/escola e trabalho/emprego, educação e desenvolvimento econômico, se estabelece a teoria do capital humano. Teoria cujos pressupostos teóricos assentam-se na economia neoclássica e na ideologia positivista/tecnicista, constituindo uma teoria do desenvolvimento e da educação, antagônicas aos interesses da classe trabalhadora. Como capital humano, a educação potencializa o emprego, perdendo sua especificidade como formação humana; funcional ao capital e perversa ao trabalho, o fracasso na obtenção de emprego e renda são imputados à (in) apropriação da escola. A base para a formação da classe trabalhadora, não é a própria classe, mas a imposição do capital fantasiado de mercado de trabalho marcado por novas tecnologias. O trabalhador e a trabalhadora no contexto da acumulação flexível devem ter sua capacidade de trabalho flexibilizada em multi-habilidades para fazer frente à rápida destruição dos postos de trabalho e às novas habilidades requeridas. A formação para o trabalho restringe-se à habilidade para o emprego - a empregabilidade (Frigotto, 2000).

A diferença aparece na perspectiva de superação dos dualismos: trabalho manual e trabalho intelectual; mundo do trabalho e mundo da escola, conhecimento técnico e conhecimento científico; educação básica e formação profissional; formação politécnica e treinamento polivalente. Visando servir o período de industrialização em andamento e cercear a capacidade reflexiva, a concepção teórica que fundamenta a legislação e as práticas escolares assenta-se no liberalismo e no tecnicismo. A prática pedagógica tecnicista tem como função especial adequar o sistema educacional à proposta econômica e política do regime militar, preparando, dessa forma, mão-de-obra para ser aproveitada pelo mercado de trabalho.

A história da educação brasileira evidencia a dicotomia entre uma formação propedêutica visando acesso à universidade e formação técnica ou profissionalização, objetivando rápida inserção no mercado, grosso modo a primeira forma destinou-se aos filhos e filhas das classes proprietárias e a segunda à prole dos não-proprietários; ainda que o 
issn: $1808-799 X$

ano 6 - número 7 - 2008

processo de democratização da escola, e conseqüente ampliação de vagas, possibilite maior inserção, também, nas instituições de ensino superior, o fosso entre a garantia de acesso e a permanência na educação superior marca a desigualdade de oportunidades sociais no país. E, permanece em disputa teórico-prática um ensino moldado ao gosto do capital e uma educação como formação geral fundada na omnilateralidade. A materialidade das práticas desnuda a irrelevância dos fundamentos legais e a precariedade das concepções tanto para a formação geral quanto para uma propalada preparação para o mercado: perdeu-se qualidade na escolarização e o valor agregado a uma perspectiva de ingresso no mercado do trabalho deuse em benefício da exploração capitalista. A classe trabalhadora teve sua escolarização fragmentada, deixando mais vulnerável a apropriação de conhecimentos tanto nos aspectos de uma formação humana quanto no que poderia ser o sentido de uma formação para o mundo do trabalho. Segue com propriedade a análise de Frigotto (1989) que aponta a produtividade da escola para o capital e sua (im) produtividade para o trabalho.

Sabemos, também, que o crescimento da dívida externa e a carestia acompanharam a volta à chamada normalidade democrática no Brasil, cada vez mais uma democracia que se expande para o capital e oprime o trabalho. Incluída nesta estrutura a temática da infância e da adolescência que, de menor, adquiriu a cidadania como sujeito de direitos. Cidadania ainda em muito restrita à letra da lei [e isso supera a especificidade etária]: os avanços propostos pelos movimentos sociais no processo da Assembléia Nacional Constituinte foram perdidos pelas negociatas no Congresso Nacional.

A Constituição de 1988, como a legislação complementar da Educação, produziu avanços nos direitos civis, entre eles o da educação como direito fundamental e definiu recursos pertinentes à garantia dos direitos inscritos. Igualdade de condições para o acesso $\mathrm{e}$ permanência na escola; gratuidade do ensino público valorização dos profissionais do ensino, garantindo, na forma da lei, plano de carreira para o magistério público, com piso salarial profissional e ingresso exclusivamente por concurso público de provas e títulos. Ensino fundamental, obrigatório e gratuito, assegurada, inclusive, sua oferta gratuita para todos os que a ele não tiveram acesso na idade própria; progressiva universalização do ensino médio gratuito; atendimento em creche e pré-escola às crianças de zero a seis anos de idade; acesso aos níveis mais elevados do ensino, da pesquisa e da criação artística, segundo a capacidade de cada um; ensino regular noturno, adequado às condições do educando; atendimento ao educando, no ensino fundamental, através de programas suplementares de material didáticoescolar, transporte, alimentação e assistência à saúde. Para o financiamento definiu a 
issn: $1808-799 \mathrm{X}$

\section{ano 6 - número 7 - 2008}

aplicação, anual, pela União de nunca menos 18\%, e os Estados, o Distrito Federal e os Municípios 25\%, no mínimo ${ }^{5}$, da receita de impostos, compreendida a proveniente de transferências, na manutenção e desenvolvimento do ensino. Apontou para um plano nacional de educação, plurianual, objetivando articular o desenvolvimento do ensino em seus diversos níveis e integrar as ações do Poder Público de maneira que haja: I - erradicação do analfabetismo; II - universalização do atendimento escolar; III - melhoria da qualidade do ensino; IV - formação para o trabalho; V - promoção humanística, científica e tecnológica do país.

A LDBEN (1996) ratifica e amplia preceitos constitucionais quanto ao dever do Estado, acesso e permanência, obrigatoriedade e gratuidade do ensino fundamental, incluídos os que não tiveram acesso na idade própria, progressiva extensão do ensino médio, educação profissional articulada à escolarização, valorização do profissional, etc. Ratifica os recursos para manutenção e desenvolvimento do ensino, definindo-os como despesas realizadas com vistas à consecução dos objetivos básicos das instituições educacionais de todos os níveis. No que refere à escolarização de jovens e adultos, portanto, para quem não teve acesso ou não conseguiu permanecer na escola, o projeto de LDB defendido pelo Fórum Nacional em Defesa da Escola Pública propugnava a oferta noturna com mesmo padrão de qualidade do ensino diurno: "educação escolar regular para jovens e adultos, com características e modalidades adequadas às suas necessidades e disponibilidades, garantindo-se aos que forem trabalhadores as condições de acesso e permanência na escola".

A história mostra que além dos recuos imputados na luta de concepções durante a elaboração dos textos legais, boa parte das práticas políticas permanece à margem da legislação. E, pelo menos dois fatores nos ajudam a compreender avanços e recuos na política brasileira nas décadas de 1980 e 1990. De um lado, ao retomar Marx, na síntese de Gramsci, nenhuma formação social desaparece enquanto as forças produtivas que nela se desenvolvam forjem lugar para um novo arranjo progressista, talvez tenhamos pistas para pensar a eterna trava no que poderia ter sido sólida ampliação no campo democrático e popular brasileiro: a forma de capitalismo dependente (Fernandes, 1975) peculiar ao Brasil, no âmbito do desenvolvimento desigual e combinado do capitalismo (Trotsky, 2003) mantém, funcionalmente, entre países de centro e de periferia e no interior dos países a desigualdade sócio-econômica, política e cultural. Assim, há desenvolvimento do subdesenvolvimento (Frank,

\footnotetext{
${ }^{5}$ A legislação específica de Estados e Municípios, em alguns casos, aumentou o percentual.
} 
issn: $1808-799 \mathrm{X}$

\section{ano 6 - número 7 - 2008}

2005) assegurando a fragilidade das instituições democráticas para mantê-las suscetíveis aos pactos burgueses. Desde a materialidade socioeconômica nunca tivemos condições de superar o subdesenvolvimento e, portanto, a ruptura com a ordem burguesa estaria entre as tarefas para cuja solução não germinaram as condições necessárias: ou, o que é o mesmo, a dependência política é condição para a dependência econômica.

De outro lado e, também combinado a esta realidade, quando chegamos ao Contrato Constitucional de 1988, no lastro dos que advieram nos campos específicos da infância e da adolescência, da Educação e da Assistência Social objetos de diálogo neste trabalho, a onda neoliberal já varria as conquistas do estado de bem-estar nos países de centro impingindo derrotas às aproximações levadas pelas lutas sociais nos países de periferia.

O cenário internacional apresentava as premissas econômicas de (re) estruturação produtiva: arranjo na esfera da produção alinhando alta tecnologia, flexibilização no processo produtivo e nas relações de trabalho, assegurando a produtividade do capital. Em nível de superestrutura, a ideologia da globalização impingiu profundas modificações na cultura, na política, nas relações sociais e pessoais. E, evidente que, também, a educação, nesse intento, sofreu mudanças para se adequar às necessidades do novo modo de acumulação.

A ampliação vertiginosa do setor de serviços e produção em escala de uma massa de desempregados estruturais, uma massa de sobrantes não apenas no mundo adulto: a tomar as políticas públicas que envolvem a faixa infanto-juvenil há evidências de uma produção não apenas conjuntural, mas estrutural de sobrantes juvenis atendidos em formas precárias de escolarização e profissionalização assegurando quantitativos para a empregabilidade, marcada por e marcante da produção flexível, pela necessidade imediata de habilidades para ocupar novos e efêmeros postos de emprego, designada capacitação, qualificação e (re) qualificação.

No Brasil, mesmo com a assinatura das Convenções 138 e 182 da Organização Internacional do Trabalho (OIT), a materialidade do desenvolvimento desigual e combinado com o subdesenvolvimento pode ser apreendida nesta conjuntura quando o padrão de acumulação gerado pelas novas tecnologias convive com o trabalho braçal pouco ou nada mecanizado, o fordismo-taylorismo e formas de associativismo na produção; também as relações de trabalho mantêm relações escravagistas, trabalho infanto-juvenil, carteira assinada e relações flexíveis que perpassam contratos precários, cooperativismo, associativismo, mas essencialmente, potencializam uma massa cada vez maior de desempregados estruturais; de sobrantes funcionais ao modo de acumulação do capital. 
issn: $1808-799 \mathrm{X}$

\section{ano 6 - número 7 - 2008}

O Estado para o capital espolia direitos, arrocha salários, precariza o trabalho docente e a escola pública (básica e superior), enfatiza o setor privado nos conselhos, introduz parâmetros de produtividade no trabalho docente, reduz tempo e valores para formação de trabalhadores da educação. Ações políticas que contextualizam a idéia de uma 'escola ampliada para menos' (Algebaile, 2004) quando as questões educacionais vão perdendo espaço e papéis correlatos às políticas de assistência social invadem a escola. CAICs de Collor, bolsa escola de Cardoso e bolsa família de Lula da Silva exemplificam políticas de governo em que se atribui à escola funções mais amplas que as propriamente escolares, sem a materialidade das condições para que sejam executadas com qualidade se quer as funções pertinentes à escola como instituição, lócus da democratização do conhecimento socialmente produzido.

Os programas bolsa escola e bolsa família, guardadas as diferenças, têm questões comuns e interface com os projetos e programas de combate ao trabalho infanto-juvenil que investiguei. Assinalo duas questões: controle quantitativo de freqüência visando pagamento de bolsa e apoio socioeducativo, sem organicidade na relação entre as políticas de Estado da Educação, Assistência Social, Esporte, Lazer, Cultura. Como políticas de governo esta infinidade de atravessamentos pulveriza recursos empoderando o setor não-governamental, acentuando o caráter reprodutivo ao fortalecer as desigualdades sociais por meios de estratégias pobres para filhos e filhas da pobreza.

\section{TEMPOS DE DESPOSSESSÃO, QUE PERSPECTIVAS PARA AS VIDAS INFANTO-JUVENIS?}

A dicotomia entre educação geral e formação especial compõe a lógica da educação capitalista, acirrada na prática cotidiana, estudada/discutida na pesquisa e sua superação continua objeto de análise e reivindicação em fóruns sindicais e acadêmicos da área educacional. Discentes e docentes nos diferentes níveis de ensino percebem o empobrecimento do currículo no que diz respeito à formação geral e lutam por sua ampliação e consistência. Cada vez mais o trabalho - como forma de assegurar a sobrevivência atravessa a educação escolar em todos os níveis, seja precoce e/ou desprotegido na escola básica sejam as jornadas que competem com o ensino superior. Conclusão fundamentada na análise do projeto social e do projeto educativo a ele associado, um e outro vincado de forma ativa, consentida e subordinada aos organismos internacionais: as formas de alívio à pobreza para iludir com o desenvolvimento as desigualdades do subdesenvolvimento. Na especificidade da educação as políticas educacionais no que refere à legislação e às reformas do ensino 
issn: $1808-799 \mathrm{X}$

ano 6 - número 7 - 2008

superior, médio e técnico ratificam os indicadores de retrocesso nos governos Cardoso e sua continuidade contemporânea.

Os governos insistem em honrar contratos pagando dívidas com o capital, opção que tem incluído não cumprir contratos e não superar as dívidas sociais: milhões de analfabetos (literais e funcionais); aumento constante de universidades em mãos privadas; funcionários de escolas sem escolaridade obrigatória; professores do ensino fundamental da rede pública contratados, portanto sem concurso; salários arrochados nos três níveis da educação pública; jornadas de trabalho intensificadas; escolas com grandes problemas de infra-estrutura e equipamentos; crescimento vertiginoso de educadores com síndrome de desistência na/da escola - na primeira situação, permanecendo sem desejo e constantemente adoecendo, e na segunda, abandonando o magistério.

Além da escola e, também em direção à sociabilidade infanto-juvenil, as concepções e práticas fundadas na ideologia da globalização e no pós-modernismo como lógica cultural, colonizam o mundo adulto e invadem definitivamente a vida de crianças, adolescentes e jovens anunciando múltiplas verdades. Multiplicidade que impõem fragmentação no lugar de totalidade, massificação de informações, e compactação e superficialidade na formação; múltiplas urgências, que justificam qualquer ética e espraiam, através da indústria cultural e das mídias, indivíduos que se movem por consumismo, individualismo, competitividade, erotismo, produtivismo, empreendedorismo; materializando a subordinação da vida social aos desígnios do capital. Borrando a visibilidade do ser social, do sujeito histórico que se produz no cotidiano das lutas de resistência pela garantia e ampliação de direitos sociais. Governo, mídia e ciência burguesa tratam de desvalorizar e tipificar como crime as lutas dos que vivem da venda de sua força de trabalho por dignidade na vida.

É nessa relação estrutura/conjuntura que trato do PETI instituído como uma política de governo que busca reparação e prevenção. Um programa do governo federal alojado no Ministério do Desenvolvimento Social que convenia com Estados e municípios, objetivando erradicar todas as formas de trabalho infantil, em um processo de resgate da cidadania de seus usuários e inclusão social de suas famílias. Combater o trabalho infantil com ações, compartilhadas entre MDS, Ministério do Trabalho Emprego e Subsecretaria de Direitos Humanos, Fundo Nacional da Assistência Social e o Fundo de Amparo ao Trabalhador. As ações envolvem apoio aos fóruns de erradicação do trabalho infantil; concessão de bolsa a crianças e adolescentes em situação de trabalho; jornada ampliada para crianças e 
issn: $1808-799 X$

\section{ano 6 - número 7 - 2008}

adolescentes em situação de trabalho; fiscalização; publicidade de utilidade pública; atualização do mapa de focos de trabalho infantil e apoio técnico à escola do futuro trabalhador.

Como política de Estado, no modo neoliberal de gestão, há falta de pessoal e de investimento no setor público encarregado: Delegacia Regional do Trabalho. Portanto, sem apoio aos fóruns, com precária fiscalização e tendo o mapa desatualizado. Como expressão da política de governo, a empiria ${ }^{6}$ vem mostrando insuficiência de bolsas PETI, ausência de diálogo entre duas das políticas de Estado envolvidas Educação e Assistência Social, concorrência com desqualificação entre dois espaços protetivos - a escola e o socioeducativo além de não se reconhecerem, disputam a proteção ao infanto-juvenil e, não raro, desqualificam a ação da outra política. Ou seja, na rede de proteção, acaba havendo um esgarçamento.

Nas disputas do Orçamento Participativo em Porto Alegre houve investimento em políticas de atenção integral à infância e adolescência, incluída a política educacional e de assistência social, com positividades. No entanto, a batalha das idéias careceu de consistência na concepção de trabalho [como princípio] educativo, ausência de formação continuada e em serviço, falta de organicidade entre as políticas para a infância e adolescência, empoderamento do setor não-governamental como parceiro nas políticas de governo, evidenciando fragilidades na medida em que a sociedade civil deixa de executar o controle social, fiscalização e avaliação, porque está comprometida com a execução das políticas.

Não há contradição entre as concepções recolhidas e as práticas políticas analisadas, políticas de menor para eternos menores, assegurando sobrantes para o capital. Há contradição entre as concepções expressas, as práticas correlatas e a natureza da questão social. Concepções que contribuem para naturalizar e produzir invisibilidade ao trabalho infantil precoce e/ou desprotegido na adolescência e, no âmbito das práticas políticas justificam ações, projetos e programas em que os governos pactuam com a sociedade civil (também com a parte que serve ao capital) para cumprir função de Estado.

Componente do modo infindável de acumulação do capital, o trabalho infanto-juvenil acirra formas de explorar e espoliar a classe trabalhadora desde a acumulação originária. $\mathrm{A}$

\footnotetext{
${ }^{6}$ Através de dois projetos de Extensão, "O PETI no socioeducativo" e "O PETI na escola", fizemos o acompanhamento neste 2008 de dois espaços - um socioeducativo e uma escola pública - que deveriam estar articulados garantindo a permanência de bolsistas PETI.
} 
issn: $1808-799 \mathrm{X}$

ano 6 - número 7 - 2008

exploração materializa-se na medida em que potencializa a criação e aprofunda mais-valia absoluta, através de mais-trabalho, uma vez que, sem proteção legal, crianças e adolescentes têm uma jornada de trabalho indefinida, servindo como elemento de pressão sobre o emprego e a jornada de trabalho do trabalhador adulto. Ainda, assegura a extração de mais-valia relativa, em níveis cada vez maiores, já que constitui um elemento de intensificação da produtividade porque com a mesma (não) qualificação do trabalhador adulto, para funções iguais, crianças e adolescentes têm sua energia vital usurpada desde a tenra idade. Espoliação asseverada quando há privação do gozo do lúdico e da fruição essenciais à infância e à adolescência cultural, emocional, física e cognitivamente saudáveis; vulnerabilizando a escolaridade e a formação humana para uma vida digna, fortalecendo no âmbito da reprodução ampliada do capital, a produção de um contingente de jovens-adultos sobrantes. Modo de reserva da força de trabalho no tempo imperialista de acumulação por despossessão.

A contradição principal do trabalho infanto-juvenil é a sua frágil capacidade como organizador do ser social (uma vez que pode ser organizador do sujeito social para a sua precariedade) e, em oposição, a força de submissão à disciplina necessária ao capital; funcionais à acumulação, constituem caráter universal à contradição porque se dão em diferentes formações sociais e, muitas vezes, mesmo quando o trabalho é adjetivado educativo. $O$ trabalho - organizador do ser social - no corte geracional e de classe tem essa capacidade esgarçada: o trabalho precoce mutila a vida infanto-juvenil.

\section{Referência Bibliográfica}

ALGEBAILE, Eveline. Escola Pública e Pobreza: expansão escolar e formação da escola para pobres no Brasil. Tese de Doutorado. UFF, Niterói, 2004.

CIAVATTA, Maria. O conhecimento histórico e o problema teórico metodológico das mediações. In: FRIGOTTO, Gaudêncio e CIAVATTA, Maria (orgs). Teoria e Educação no Labirinto do Capital. Rio, Petrópolis, Vozes, 2001.

ENGELS, Friedrich. La situación de la clase obrera en Inglaterra. http://www.marxists.org/portugues/engels/index.htm. 21/05/2003.

FERNANDES, Florestan. Capitalismo Dependente e Classes Sociais na América Latina. Rio de Janeiro: Zahar, 1975. 
issn: $1808-799 X$

ano 6 - número 7 - 2008

FRANK, André Gunder. El desarrollo del subdesarrollo. In: Montly Review, selecciones en castellano. El nuevo rostro del capitalismo rupturas y continuidades en la economía-mundo (volumen I). Barcelona, Espanha: Hacer editorial en coedición con Món-3, 2005.

FRIGOTTO, Gaudêncio. A produtividade da escola improdutiva. Um (re) Exame das relações entre Educação e Estrutura Econômico-Social Capitalista. São Paulo: Cortez, 1989.

As relações trabalho-educação e o labirinto do Minotauro. In: AZEVEDO, J.C.; GENTILI, P.; et alli. Utopia e Democracia na Educação Cidadã. Porto Alegre: Editora da Universidade, 2000.

HARVEY, David. O novo imperialismo. São Paulo: Loyola, 2004.

LENIN, V.I. El Estado y La Revolución. Obras Escogidas. Moscú: Editorial Progreso, s/d.

MARX, Karl. Critica del Programa de Gotha. In: MARX e ENGELS. Obras Escogidas. Moscú: Editorial Progreso, s/d.

El Capital I. Crítica de la Economía Política. México: Fondo de Cultura Económica Clásicos de Economía, 1991.

MARX e ENGELS. Textos sobre Educação e Ensino. São Paulo: Moraes, 1992.

ORGANIZAÇÃO INTERNACIONAL DO TRABALHO. Convenção $N^{\circ} 138$. Sobre a Idade Mínima para Admissão de Emprego. http://www.oit.orgbrasilia, 2002.

ORGANIZAÇÃO INTERNACIONAL DO TRABALHO. Convenção $N^{\circ} 182$. Sobre Proibição das Piores Formas de Trabalho Infantil e Ação Imediata para sua Eliminação. http://www.oit.org/brasilia, 2002.

PISTRAK, M. M. Fundamentos da Escola do Trabalho. São Paulo: Expressão Popular, 2000.

TROTSKY, Leon. El desarrollo desigual y combinado y el papel del imperialismo yanqui.http://www.ceip.org.ar/escritos/Libro3/html/T04V120.htm\# ftn1, 29/07/2003. 